\title{
The Ionospheric Precursor to the 2011 March 11 Earthquake Based upon Observations Obtained from the Japan-Pacific Subionospheric VLF/LF Network
}

\author{
Masashi Hayakawa ${ }^{1,2,3,4, *}$, Yasuhide Hobara ${ }^{5,2}$, Alexander Rozhnoi ${ }^{6}$, Maria Solovieva ${ }^{6}$, \\ Kenji Ohta $^{7}$, Jun Izutsu ${ }^{7}$, Tohru Nakamura ${ }^{8}$, and Yasushi Kasahara ${ }^{5}$ \\ ${ }^{1}$ Advanced Wireless Communications Research Center, The University of Electro-Communications (UEC), Tokyo, Japan \\ ${ }^{2}$ Research Station on Seismo Electromagnetics, The University of Electro-Communications (UEC), Tokyo, Japan \\ ${ }^{3}$ Hayakawa Institute of Seismo-Electromagnetics, Co. Ltd., UEC Incubation Center, Tokyo, Japan \\ ${ }^{4}$ Earthquake Analysis Laboratory, Information Systems Inc., Tokyo, Japan \\ ${ }^{5}$ Graduate School of Informatics and Engineering, The University of Electro-Communications (UEC), Tokyo, Japan \\ ${ }^{6}$ Institute of Physics of the Earth, Russian Academy of Sciences, Moscow, Russia \\ ${ }^{7}$ Department of Electronic Engineering, Chubu University, Kasugai Aichi, Japan \\ ${ }^{8}$ Department of Physics, Kochi University, Kochi, Japan
}

Received 10 May 2012, accepted 14 December 2012

\begin{abstract}
By using network observation of subionospheric VLF (very low frequency)/LF (low frequency) signals in Japan and in Russia, we have found a significant ionospheric perturbation prior to the recent 2011 March 11 Japan earthquake (EQ) which occurred at sea proximate to the Tohoku area on the main island (Honshu) of Japan was an exceptionally huge plate-type EQ. A remarkable anomaly (with a decrease in the nighttime amplitude and also with enhancement in dispersion) was detected on March 5 and 6 along the propagation path from the NLK (Seattle, USA) transmitter to Chofu (together with Kochi and Kasugai). We also have observed the corresponding VLF anomaly during a prolonged period of March 1 - 6, with minima in the nighttime amplitude on March 3 and 4 along the path from JJI (Miyazaki, Kyushu) to Kamchatka, Russia. This ionospheric perturbation has been discussed extensively with respect to its reliability. (1) How abnormal is this VLF/LF propagation anomaly? (2) What was the temporal evolution of terminator times? (3) Were there any solar-terrestrial effects (especially the effect from geomagnetic storms) on the VLF/LF propagation anomaly? (4) The effect of any other EQs and foreshock activities on the VLF/LF anomaly? (5) Were there any correlations with other related phenomena? Finally, (6) are there any other examples of a VLF/LF propagation anomaly for oceanic EQs? We then compared the temporal properties of ionospheric perturbations for this EQ with those of a huge number of inland EQs and compared the corresponding spatial scale with the former result of the same oceanic 2004 Sumatra EQ with nearly the same magnitude. Finally, the generation mechanism of those seismo-ionospheric perturbations is briefly discussed.
\end{abstract}

Key words: Ionospheric precursor, VLF/LF subionospheric propagation, 2011 March 11 Japan earthquake

Citation: Hayakawa, M., Y. Hobara, A. Rozhnoi, M. Solovieva, K. Ohta, J. Izutsu, T. Nakamura, and Y. Kasahara, 2013: The ionospheric precursor to the 2011 March 11 earthquake based upon observations obtained from the Japan-Pacific subionospheric VLF/LF network. Terr. Atmos. Ocean. Sci., 24, 393408, doi: 10.3319/TAO.2012.12.14.01(AA)

\section{INTRODUCTION}

It has been recently shown that there exist electromagnetic precursors to earthquakes (EQs) (e.g., Hayakawa 1999, 2009a; Hayakawa and Molchanov 2002; Pulinets and Boyarchuk 2004; Molchanov and Hayakawa 2008; Uyeda

\footnotetext{
* Corresponding author

E-mail: hayakawa@hi-seismo-em.jp
}

et al. 2009; Hayakawa and Hobara 2010). The observation of seismo-electromagnetic and related phenomena can be customarily classified into the two categories: (1) direct effects emitted from the lithosphere and received on the Earth's surface, and (2) the indirect effects of EQs which are the perturbations (or disturbances) taking place either in the atmosphere or in the ionosphere due to pre-EQ lithospheric 
activities. As for the first category, there are observed lithospheric emissions in a wide frequency range from DC (direct current)/ULF (ultra low frequency) to VHF or even higher. The first example is the DC geoelectric signals (Varotsos 2005); and, the second is ULF electromagnetic emissions which seem to be very promising for EQ prediction [e.g., see the reviews by Hayakawa et al. (2007), Fraser-Smith (2009), and Kopytenko et al. (2009)]. As for the second category, there are several techniques to reveal pre-EQ atmospheric and ionospheric precursors, including satellite infrared sensors, vertical sounding of the ionosphere from the ground, GPS observation, in-situ plasma observation, etc. (e.g., Hayakawa 2012) and, probing by anomalous propagation of radio waves. The further reviews on the second category have been published regarding the atmospheric perturbations by Hayakawa (2009b) and on the ionospheric perturbations by Hayakawa (2009c), Liu (2009), and Parrot (2009).

Among different kinds of electromagnetic precursors mentioned above, the ionospheric perturbations which belong to the second category seem to be the most reliable because a substantial number of VLF/LF work have been accumulated including both cases and statistical studies [as summarized in Hayakawa (2009c)] since the initial work by Gokhberg et al. (1989) and Gufeld et al. (1992). Recently the lower ionospheric perturbation as detected by subionospheric VLF/LF propagation is shown to be statistically significantly correlated with EQs which take place within the wave sensitive area of the great-circle path and with magnitude tentatively greater than 6.0 and shallower depth $(<40 \mathrm{~km})$ (Hayakawa et al. 2010a, b). These papers were based on an abundant number of land EQs over seven years which lend a further support to our previous similar statistical studies although based upon a fewer number of events and over smaller time periods (Rozhnoi et al. 2004; Maekawa et al. 2006; Kasahara et al. 2008; Chakrabarti 2010). The similar statistical correlation also has been obtained by Liu et al. (2006) between the upper ionosphere and EQs on the basis of vertical sounding from the ground and GPS TEC (Total electron contents) observation. Together the studies suggest that the ionosphere not only in the lower region but also is extremely sensitive to the pre-seismic activity in the F2 layer. A few possible mechanisms for seismo-ionospheric perturbations have already been proposed (e.g., Hayakawa et al. 2004; Pulinets and Boyarchuk 2004; Molchanov and Hayakawa 2008) but it is not well understood and which mechanism is dominant (Hayakawa et al. 2011).

In parallel with the above-mentioned statistical studies, we are also interested in case studies for huge EQs because those case studies are of vital importance in investigating the detailed temporal/spatial characteristics of such seismoionospheric perturbations and also their relationship with corresponding lithospheric and atmospheric phenomena. Our former case studies include the (1) Kobe EQ (17 Janu- ary 1995) (Hayakawa et al. 1996), (2) Tokachi-oki EQ (25 September 2003) (Shvets et al. 2004; Cervone et al. 2006), (3) Niigata-chuetsu EQ (23 October 2004) (Hayakawa et al. 2006; Yamauchi et al. 2007), (4) the 1999 Chi-chi EQ in Taiwan (Hayakawa et al. 2005) and, (5) the 2004 Sumatra EQ (Horie et al. 2007a, b). The details of seismogenic effects for these EQs are summarized in our review by Hayakawa (2009c). All of these EQs except the Tokachi-oki and Sumatra EQs were of the land-type EQs due to fault activity; thus, we are very familiar with the characteristics of seismoionospheric perturbations for land EQs together with the above-mentioned statistical studies (e.g., Hayakawa et al. 2010a, b).

The 2011 Japan EQ was extremely huge with a magnitude of 9.0 and is also characterized by an oceanic EQ taking place in the Pacific Ocean due to plate movement leading to a premise for us to show whether the ionospheric perturbation is generated prior to this oceanic EQ and, if so, to compare the characteristics of seismo-ionospheric perturbation for this sea EQ with the former properties of many land EQs.

\section{THE 2011 TOHOKU EQ}

An extremely huge EQ (with magnitude of 9.0) occurred under the sea bed in the Pacific Ocean off the Tohoku area of Japan, which is formally named the EQ of the 2011 off the Pacific coast of Tohoku. This EQ took place at 14:46:18 LT on March 11, 2011 with its epicenter at the geographic coordinates $\left(36^{\circ} 6.2^{\prime} \mathrm{N}, 142^{\circ} 51.6^{\prime} \mathrm{E}\right)$ as shown in Fig. 1 by a red star with its date and its depth of $\sim 20 \mathrm{~km}$. This EQ is a very typical oceanic EQ of the plate type around Japan which is very different from the extensively-studied fault-type EQs such as the Kobe EQ (Hayakawa et al. 1996) and the Niigata-chuetsu EQ (Hayakawa et al. 2006; Yamauchi et al. 2007).

\section{VLF/LF SUBIONOSPHERIC NETWORK}

We established our Japanese and Pacific network for subionospheric VLF/LF propagation just after the 1995 Kobe EQ within the framework of the former NASDA's frontier project (Hayakawa et al. 2004). This network observation has been in continuous operation to date. The main observatories within Japan at the moment are (1) Moshiri (abbreviated as MSR) in Hokkaido, (2) Chofu (CHF) in Tokyo, (3) Kasugai (KSG) near Nagoya, (4) Kochi (KCH) on Shikoku island, and (5) Tsuyama (TYM), Okayama as shown by red stars in Fig. 1, although TYM was not illustrated in the figure. Some additional observatories are planned to be built shortly. At each receiving station we normally detect simultaneously the signals from two Japanese transmitters with call signs of JJY (in Fukushima, $40 \mathrm{kHz}$ ) and JJI (in Miyazaki, Kyusyu, $22.2 \mathrm{kHz}$ ) as shown by blue diamonds in 


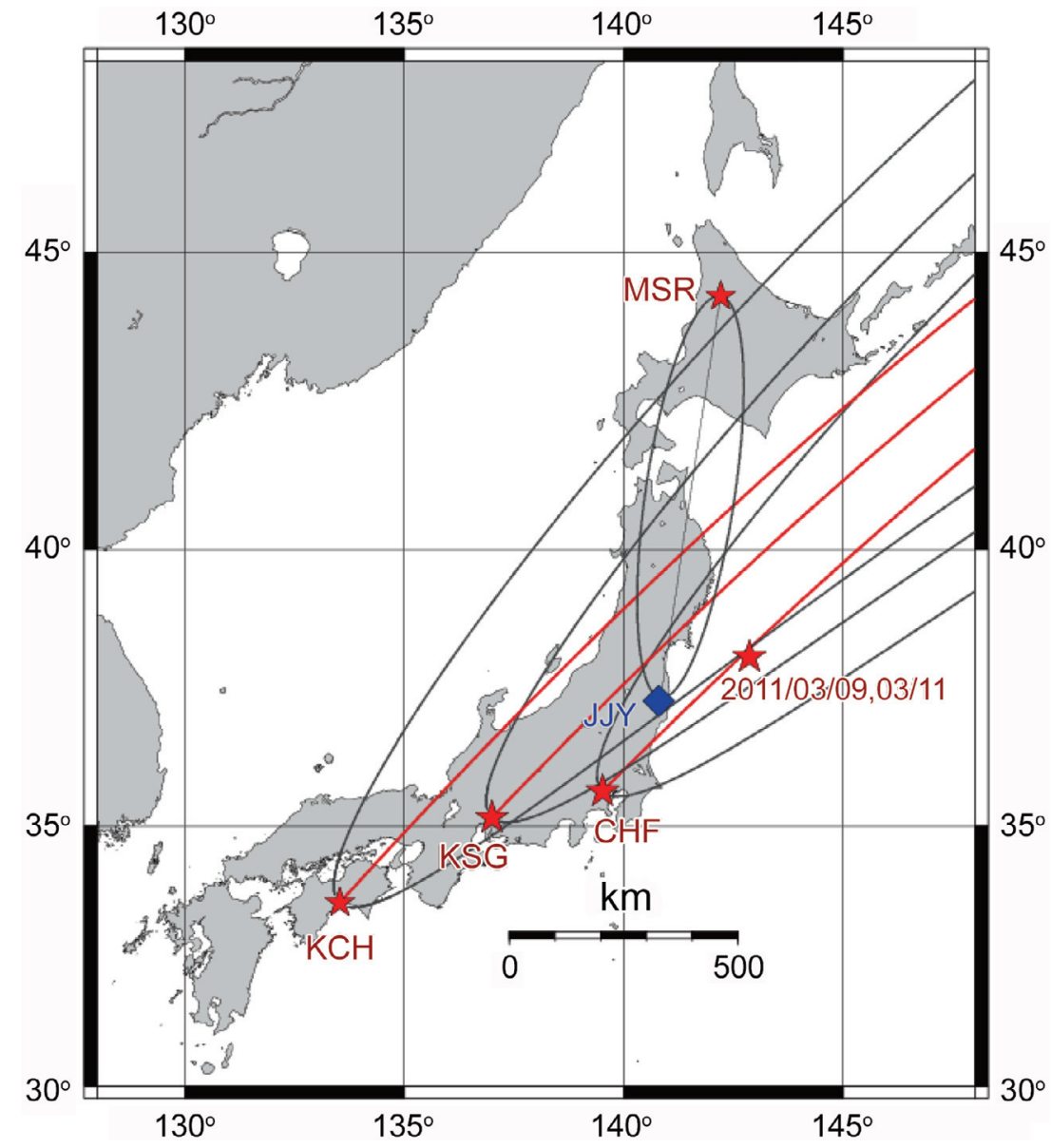

Fig. 1. The relative locations of two Japanese VLF/LF transmitters (with call signs of JJY (Fukushima) and JJI (Miyazaki) indicated by blue diamonds) and VLF/LF receiving stations (Moshiri (MSR), Chofu (CHF), Kasugai (KSG) and Kochi (KCH) shown with red stars). The wave sensitive area defined by the Fresnel zone (elliptic zone) for the propagation path of JJY-MSR is plotted, and also that for the propagation path of NLK (Seattle, USA) - CHF is plotted. Further, the great-circle paths (in red thin lines) and the corresponding wave sensitive areas (in black thin lines) are indicated for the paths of NLK-KSG and NLK-KCH. The epicenters of the main shock and its foreshock are indicated with red stars with the corresponding dates.

Fig. 1 and also a few foreign transmitters [i.e., NWC (North West Cape, Australia), NPM (Hawaii) and NLK (Seattle, USA)]. The details of this VLF/LF network and corresponding VLF receiving system can be found in Hayakawa et al. (2004, 2010a, b) and Hayakawa (2009c).

This subionospheric VLF/LF network has been extended to cover a wider area of the Pacific ocean, including one station in Russia, Petropavlovsk-Kamchatsky (PTK) shown as a green dot in Fig. 2 in collaboration with Russian colleagues (Uyeda et al. 2002; Molchanov and Hayakawa 2008) and another station in Taiwan (Hayakawa et al. 2010c). Observations at PTK have been performed regularly resulting in significant scientific output (Rozhnoi et al. 2004, 2007, 2012a, b). The Russian group has recently established one more station, Yuzhno-Sakhalinsk (abbreviated as YSH and shown as a green dot in Fig. 2). These two stations are equipped with the same type of VLF/LF receiving system used at Japanese stations.

\section{OBSERVATIONAL RESULTS AND ANALYSIS METHOD}

Figure 1 illustrates one path from JJY to MSR [and its corresponding $5^{\text {th }}$ Fresnel zone as the wave sensitive area (elliptic zone)] and the three paths from NLK (Seattle, USA) to Japanese VLF/LF observatories (CHF, KSG and $\mathrm{KCH})$. Furthermore, the $5^{\text {th }}$ Fresnel zones for the propagation paths from NLK to CHF, KSG and KCH are plotted in thin black lines which are the wave sensitive areas for these paths and are much bigger than that for the path from JJY to MSR because the NLK-CHF propagation distance is much larger than that for JJY-MSR path. The wave sensitive area is defined in such a way that any EQs taking place within this area can result in a certain significant influence on the signal received at the observatory as a propagation anomaly (either in amplitude or in phase, or both). How to determine the width of an elliptic zone is described, for example, in Rozhnoi et al. (2012a). 


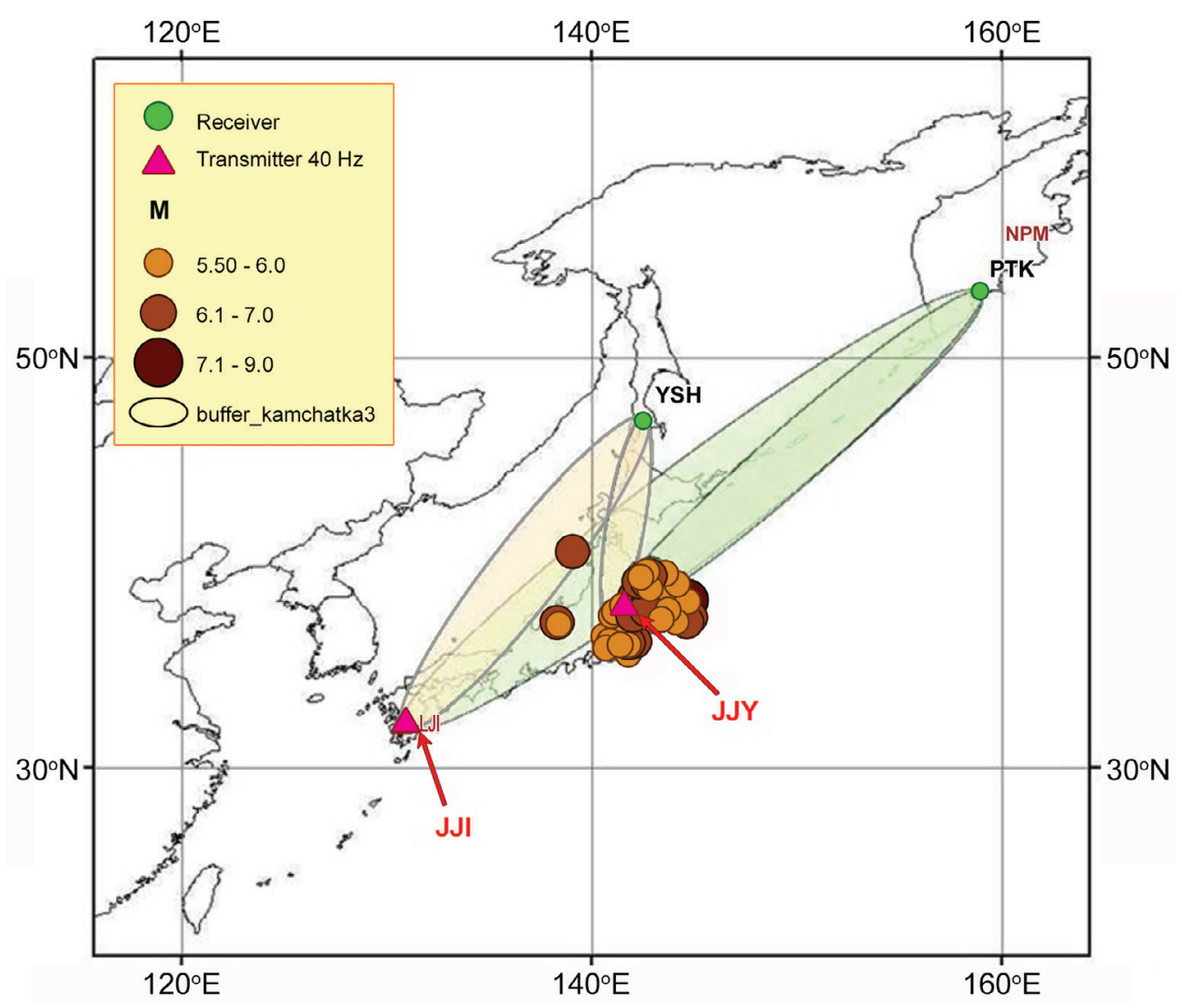

Fig. 2. Relative locations of the two Japanese VLF/LF transmitters (JJY and JJI in triangles) and two observing stations [Petropavlovsk-Kamchatsky (PTK) and Yuzhno-Sakhalinsk (YSH) as small green dots]. The wave sensitive areas (elliptic zones) for the propagation paths of JJY-YSH, JJYPTK, JJI-YSH and JJI-PTK are plotted. Further, the main shocks and aftershocks are plotted, with their sizes being proportional to EQ magnitude.

As for the analysis method in this paper, we do not follow the terminator-time method as initially developed for the Kobe EQ (Hayakawa et al. 1996), but apply an alternative way of "the nighttime fluctuation method" (Rozhnoi et al. 2004; Maekawa et al. 2006; Kasahara et al. 2008; Hayakawa et al. 2010a, b) in which we pay attention only to the nighttime amplitude data. Nighttime data are chosen in such a way that nighttime is well separated from terminator times. We first read the temporal evolution of amplitude $\mathrm{A}(\mathrm{t})$ at a current time $\mathrm{t}$ during the local nighttime on a particular day, while $\langle\mathrm{A}(\mathrm{t})\rangle$ is estimated as the average amplitude at the same time $t$ during the period from one day to 30 days before the current day. Then, we can estimate the residue $\mathrm{dA}(\mathrm{t})=\mathrm{A}(\mathrm{t})-\langle\mathrm{A}(\mathrm{t})>$. Using this residue, we can estimate the most important parameter, trend as the nighttime average amplitude [mean value of $\mathrm{dA}(\mathrm{t})$ over local time]. The second parameter is dispersion which is characterized by how much the amplitude fluctuates around the average. These two parameters are independent variables. All of these parameters are normalized by their corresponding standard deviations $(\sigma)$ over $30^{\text {th }}$ to the day before the current day of the event. Further details of this nighttime fluctuation method can be found in Kasahara et al. (2008) and Hayakawa et al. (2010a, b).

As for the definition of a nighttime period, we take the UT period of UT $=11-19 \mathrm{~h}$ for the propagation path from JJY to MSR because the LT in Japan $=\mathrm{UT}+9 \mathrm{~h}$. While the definition of nighttime is considerably complicated for the east-west long-distance propagation from NLK to Japanese stations (such as $\mathrm{CHF}$ ) (distance $=7-8 \mathrm{Mm}$ ). By considering the sunrise and sunset both at the transmitter and receiving observatory [that is, terminator times (Hayakawa et al. 1996)] and also checking the real diurnal variations for the relevant NLK-CHF path, we have taken UT $=10$ to $12 \mathrm{~h}$ for the nighttime for the NLK-CHF path (that is, only during this period the propagation path is completely in the dark).

Figure 2 illustrates the relative location of the Japanese VLF/LF transmitters (JJY in Fukushima and JJI in Miyazaki) which can be seen in Fig. 1 as well and two Russian observatories, PTK and YSH. The wave sensitive areas for all combinations of transmitter-receiver, are also shown (i.e., JJY-YSH, JJY-PTK, JJI-YSH, and JJI-PTK), together with the locations of the main shock and aftershocks.

Next we have to discuss the nighttime interval for the Russian data because we use the same nighttime fluctuation method. The night in February is UT = 10:30 - 18:40 and UT 
$=11: 00-16: 30$ for May. Correspondingly, the nighttime for March and April is within this interval; UT $=10: 30-11: 00$ for sunset and 16:30 - 18:40 for sunrise. The data analysis for Russian data is exactly the same as the data analysis for Japanese data as mentioned above. The analysis period is taken from January 1 to May 22, 2011, including our target EQ on March 11.

Figure 3 illustrates the temporal profiles of $\mathrm{dA}(\mathrm{t})$ for one particular path of NLK-CHF only on a few days [March 1 (Fig. 3a), March 5 and 6 (Figs. 3b and c)]. In each panel, the top two curves are $\langle\mathrm{A}(\mathrm{t})\rangle$ (smooth) and $\mathrm{A}(\mathrm{t})$ (variable); and, the bottom curve is the residue $\mathrm{dA}(\mathrm{t})[=\mathrm{A}(\mathrm{t})-\langle\mathrm{A}(\mathrm{t})>]$. Also, the time interval, UT $=10-12 \mathrm{~h}$ is indicated by two vertical lines, which is subjected to our analysis. It is clear from this figure that the propagation is perturbed on March 5 and 6 compared with the quiet day of March 1; the quantitative estimation will be presented later.

\subsection{No Precursory Propagation Anomaly for JJY-MSR, JJY-YSH and JJI-YSH}

Unlike the 2005 Miyagi-oki EQ (Muto et al. 2009), the epicenter of this $3.11 \mathrm{EQ}$ was found to be located considerably distant from the JJY-MSR path wave sensitive area, because this EQ occurred $\sim 150 \mathrm{~km}$ away from the coast line of the Tohoku area (Hayakawa et al. 2012).
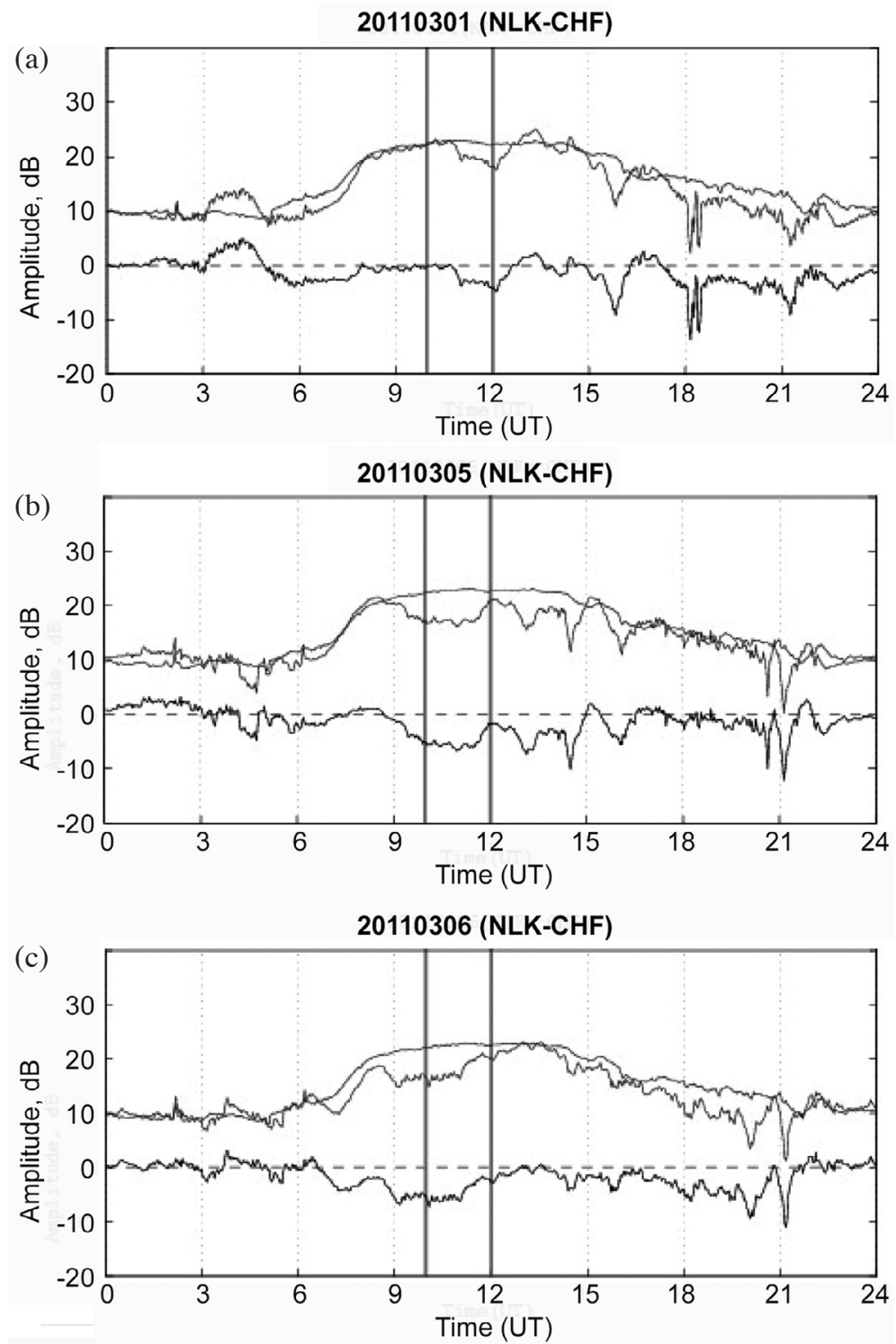

Fig. 3. Examples of diurnal variations of VLF data for the path of NLK-CHF. (a) March 1 is a seismically quiet day, while the two days of (b) March 5 and (c) March 6 are the most disturbed days. In each panel the smooth one of the two top curves is $\langle\mathrm{A}(\mathrm{t})\rangle$. Another variable curve is the diurnal variation $[\mathrm{A}(\mathrm{t})]$ on the current day. Then, the bottom is the difference $\mathrm{dA}(\mathrm{t})[=\mathrm{A}(\mathrm{t})-<\mathrm{A}(\mathrm{t})>]$. Also, the 2 hour between $\mathrm{UT}=10$ and $12 \mathrm{~h}$ is the period when the whole propagation path from the transmitter to the receiver is in complete darkness, which is subject to our analysis. 
Though not shown as a figure in this paper, we have found, in our latest paper (Hayakawa et al. 2012) based on our preliminary analysis that there is definitely no time interval from March 1 to March 9 before the EQ on the JJYMSR path in which the trend shows a notable decrease together with the simultaneous increases in the dispersion as in the case of a tremendous number of land EQs.

Next we analyzed the propagation paths of JJY-YSH and JJI-YSH. The path of JJY-YSH is relatively close to the previous path of JJY-MSR as seen in Fig. 2 because the JJY-YSH path is likely to be just an extension of the JJYMSR path. We have analyzed the paths of JJY-YSH and JJI-YSH, but we have not found any definite significant effects (no propagation anomalies) on these paths, though not presented as figures.

\subsection{Significant Propagation Anomalies Associated with the Propagation Paths for the American transmitter NLK}

Figure 1 suggests that the propagation paths from Japanese receiving stations $(\mathrm{CHF}, \mathrm{KSG}$, and $\mathrm{KCH})$ to the American transmitter NLK (at Seattle, USA) are favorably located with respect to the epicenter of this oceanic EQ and is especially so for the NLK-CHF path is passing just above the EQ epicenter; the corresponding wave sensitive area for this NLK-CHF path is plotted in a thin line in Fig. 1. Two other propagation paths from NLK to KSG and from NLK to $\mathrm{KCH}$ are also favorable for us to detect any corresponding ionospheric perturbations.

In response to these theoretical expectations, Figs. $4 \mathrm{a}-\mathrm{c}$ illustrate the real temporal evolutions of propagation characteristics for these relevant paths; Fig. 4a refers to the NLK-CHF path, Fig. 4b, NLK-KSG path, and Fig. 4c, the NLK-KCH path. In Figs. $4 \mathrm{a}-\mathrm{c}$ we have illustrated, from top to the bottom, the trend and dispersion, with these parameters being all normalized by their corresponding standard deviations $(\sigma)$. Let us look at the top panel (on trend) of Fig. 4a for the most important propagation path from NLK to CHF during the period from January 1 . We have found that the trend does not drop down to a $-2 \sigma$ level over the entire period, except on January 29 and an extremely significant propagation anomaly on the two days of March 5 and 6. The propagation anomaly on March 5 is characterized by a remarkable decrease in trend (exceeding $-3 \sigma$ or even approaching $-4 \sigma$ ), together with the nearly simultaneous increases in the second parameter (dispersion) (approaching $+2 \sigma$ ). The corresponding anomaly is also recognized in Fig. $4 \mathrm{c}$ for the propagation path from NLK to $\mathrm{KCH}$. The anomaly for this path is rather evident in such a way that the most important parameter, trend exhibited a significant decrease reaching $-2 \sigma$ level. On the other hand, the anomaly for the path of NLK to KSG in Fig. 4b is less enhanced on the same days of March 5 and 6, but it is important to note that the response to this EQ is very evident.

Although as viewed from Fig. 1 that the NLK-KSG path is closer to the EQ epicenter than the NLK-KCH path. The anomaly intensity is not consistent with this situation. So that, it would be nice to see a dependence of the strength of anomaly on the distance. We tentatively define the distance of the propagation path to the EQ epicenter by the length from the EQ epicenter of a line perpendicular to each propagation path. The result of the anomaly effect versus distance (d) can be summarized as follows. As seen from Fig. 4, $\mathrm{d}=10 \mathrm{~km}$ (CHF-NLK) yields the anomaly of $-3.8 \sigma,-0.8 \sigma$ for $\mathrm{d} \sim 116 \mathrm{~km}$ (KSG-NLK) and $-2.0 \sigma$ for $\mathrm{d}$ $\sim 200 \mathrm{~km}$ (KCH-NLK). It is likely that the anomaly exceeding the $-2 \sigma$ criterion takes place for the distance (d) less than $\sim 200 \mathrm{~km}$.

Here we should comment on other propagation anomalies seen in Figs. $4 a$ - c. In our recent paper (Hayakawa et al. 2010a) we have tentatively chosen an EQ magnitude threshold of $\mathrm{M}=6$ (only rather strong EQs) and we have obtained a quite significant correlation exceeding well beyond the $2 \sigma$ criterion. However, even if we lower the magnitude threshold down to $\mathrm{M}=5.5$, we know that the correlation between VLF/LF anomalies and EQs is still significant, just around 2 $\sigma$ level (Rozhnoi et al. 2004; Maekawa et al. 2006). Therefore, we try to associate other depletions in trends in Figs. $4 \mathrm{a}$ - $\mathrm{c}$ to EQs in the relevant region. First, we comment on the anomaly of January 29 in Fig. 4a. Probably in possible association with this anomaly, there happened to have occurred two EQs off the coast of Iwate (on February 3 ) and Fukushima (on February 10, $\mathrm{M}=5.3$ ). Further comments are required on other depletions in trend in Fig. 4c. The depletion on January 23 is likely to be related with an EQ off the coast of Chiba on January 25 ( $M=5.1)$. Then, the depletions in trend on February 1 and 8 (exceeding $-2 \sigma$ level) are likely to be related to another EQ in Chiba-oki on February $5(\mathrm{M}=5.2)$ and to an EQ in the Miyagi-oki on February $15(\mathrm{M}=5.5)$, respectively. Finally, the depletion on February 5 in Fig. $4 \mathrm{~b}$ is likely to be a precursor to an EQ in Fukushima-oki $(\mathrm{M}=5.3)$.

\subsection{Clear Propagation Anomaly for the Propagation Path from JJI to PTK}

Among the three Russian propagation paths, we have found a conspicuous effect only on the propagation path from JJI (Miyazaki, Kyushu) to PTK (Kamchatka). Figure 5 illustrates the temporal evolution of the nighttime average amplitude (trend) (top panel). The second panel refers to the conventional dispersion and the bottom [what] indicates the evolution of the EQs with a magnitude greater than 5.5. In the top panel, horizontal dotted lines indicate the $2 \sigma$ and $-2 \sigma$ levels. In the middle panel of dispersion, the $+2 \sigma$ line is again plotted as a horizontal dotted line. Figure 5 shows that a significant and prolonged decrease in nighttime amplitude 
takes place during a rather long period from February 28 to March 6 on the path from JJI to PTK with a maximum depletion on March 3 and 4. The corresponding increases in dispersion are simultaneously observed during the same prolonged period with the maximum on March 3 and 4 . The dates with VLF/LF propagation anomaly on the Russian path are shifted somewhat compared with that for the NLK-CHF path in Fig. 4; but, the anomaly on this propagation path is considered to be the same one for the previous propagation path of NLK-CHF because we know that there exists some inhomogeneity in the time and space of the ionospheric per- turbation (e.g., Yamauchi et al. 2007).

Finally, we comment on the last Russian path, JJYPTK. The wave sensitive area for this propagation path is seen from Fig. 2 to be completely within the wave sensitive area of the above-mentioned JJI-PTK path with significant anomalies. Though not shown as a figure, it is found that the trend shows a significant decrease on March 4, but not exceeding $-2 \sigma$, but approximately $-1.5 \sigma$. Finally, an anomaly is observed for this path as well on March 4, but this nature is indicative of highly heterogeneous property of the ionospheric perturbation.

(a)
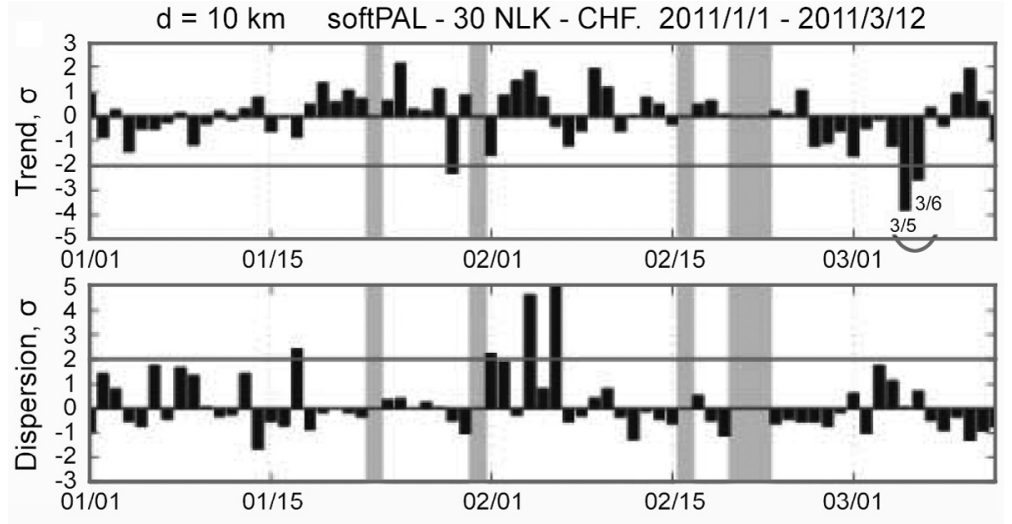

(b)
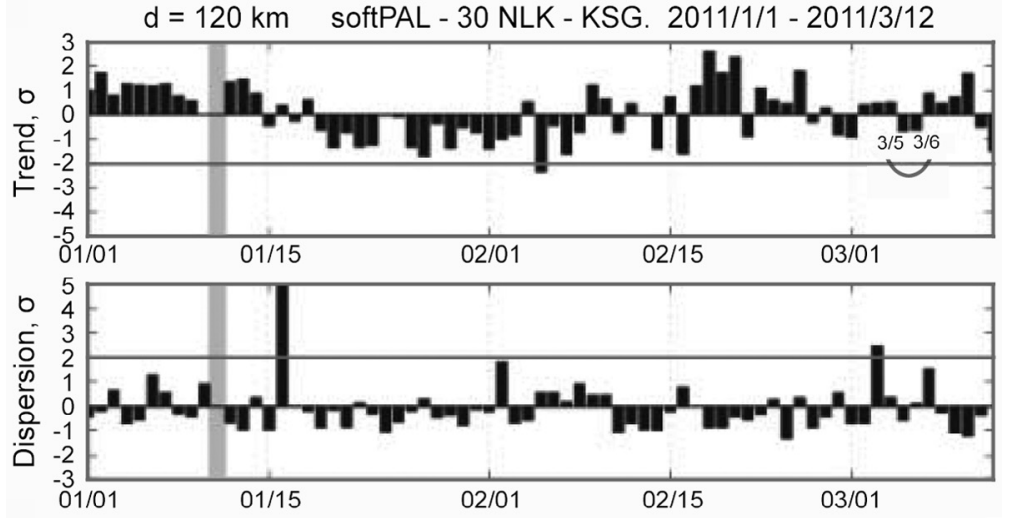

(c)
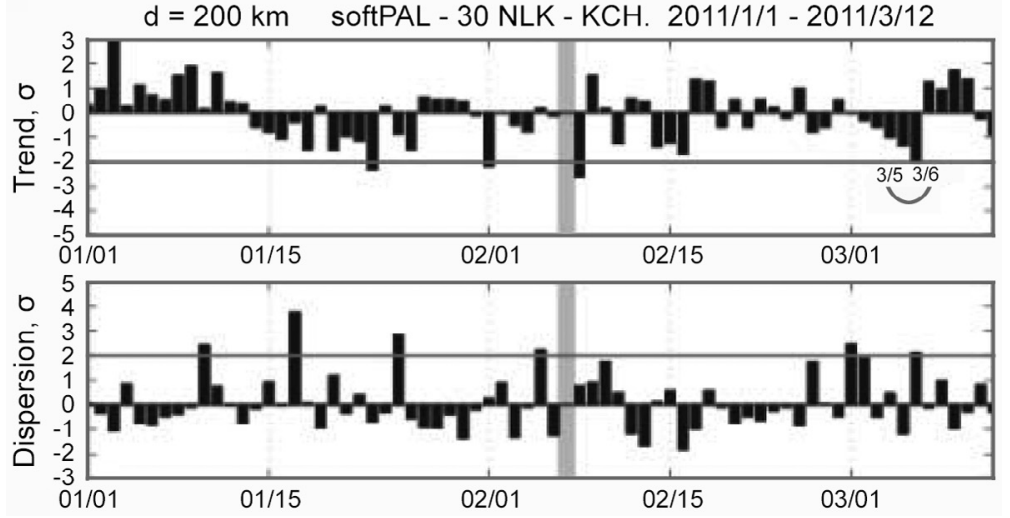

Fig. 4. Temporal evolutions of the propagation characteristics for the three propagation paths, (a) NLK-CHF, (b) NLK-KSG, and (c) NLK-KCH. In each figure, the top panel refers to the average nighttime amplitude (called trend), and the bottom, to the dispersion. All of these values are normalized by their corresponding standard deviations $(\sigma)$. A clear anomaly is seen on March 5 and 6 . The distance of EQ epicenter to each propagation path (d) is indicated on the top left in each figure. 


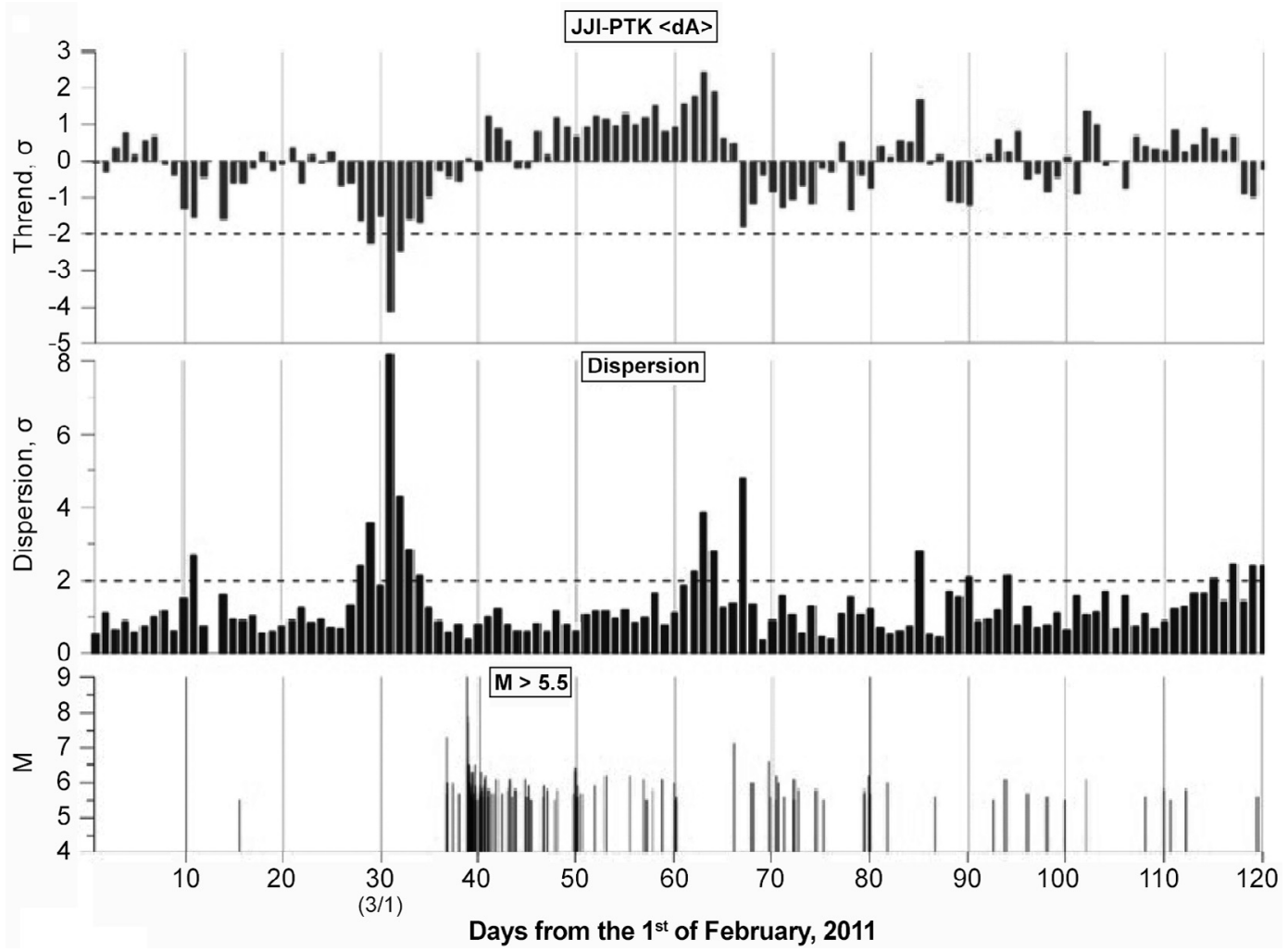

Fig. 5. Temporal evolution of the propagation characteristics for the propagation path of JJI-PTK. The top panel refers to the average nighttime amplitude (corresponding to the trend in Fig. 3) (horizontal broken line indicates - $2 \sigma$ level), and the middle panel, the dispersion (horizontal broken line, $+2 \sigma$ level). Again, both parameters are normalized by their standard deviations $(\sigma)$. The bottom panel indicates the temporal evolution of the seismic activity.

\section{SUMMARY AND DISCUSSION}

By making full use of the Japanese-Russian subionospheric VLF/LF network, the following observational facts have emerged in possible relation to the March 11, 2011 3.11 Japan EQ.

(1) No definite anomaly has been detected for the three propagation paths of JJY-MSR, JJY-YSH and JJI-YSH.

(2) On the other hand, clear and significant propagation anomalies have been observed for the two propagation paths of the NLK-Japanese stations (CHF, KSG and $\mathrm{KCH}$ ) and JJI-PTK. The propagation anomaly for the path NLK-CHF takes place on March 5 and 6, which is characterized by a significant decrease in trend (nighttime average amplitude) well exceeding the $-3 \sigma$ level, together with the simultaneous increases in dispersion. While, the anomaly on the path of JJI-PTK shows a broad depletion from February 28 to March 6, with maximum depletions on March 3 and 4, which is also characterized by a significant decrease in tend and an increase in dispersion. So, the remarkable ionospheric perturbation is likely to be persistent, at least, for 4 days (March 3 - 6).
Here we try to convince the readers that our anomalous changes in VLF/LF propagation summarized above would be highly likely to be related with the $3.11 \mathrm{EQ}$. The following points will be discussed. (1) How exceptional is this VLF/LF propagation anomaly (the significance of the use of conventional standard deviation)? (2) How about the temporal evolution of terminator times (any significant change in terminator-times)? (3) Any solar-terrestrial effects (especially the effect of geomagnetic storms) on the VLF/LF propagation anomaly? (4) The effects of any other EQs and foreshock activities on the VLF anomaly? (5) Any correlation of the present anomaly with other related phenomena? and (6) any other examples of VLF/LF propagation anomaly for oceanic EQs?

\section{(1) How Abnormal is This VLF Propagation Anomaly?}

When looking at the temporal evolutions of VLF/LF propagation parameters (trend and dispersion) in Figs. 4a, b, and $\mathrm{c}$, one is suspicious about the use of standard deviation $(\sigma)$ when the distribution of trend values is not Gaussian. Figure 6 illustrates the distributions of occurrence numbers of (a) trend values and (b) dispersion (in Fig. 3) during the 
(a)

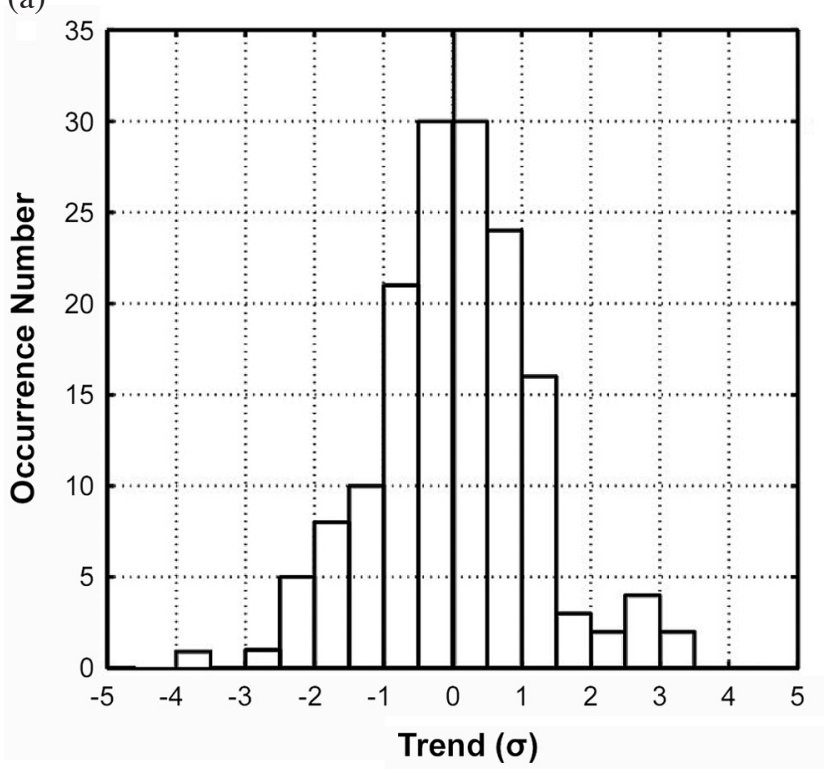

(b)

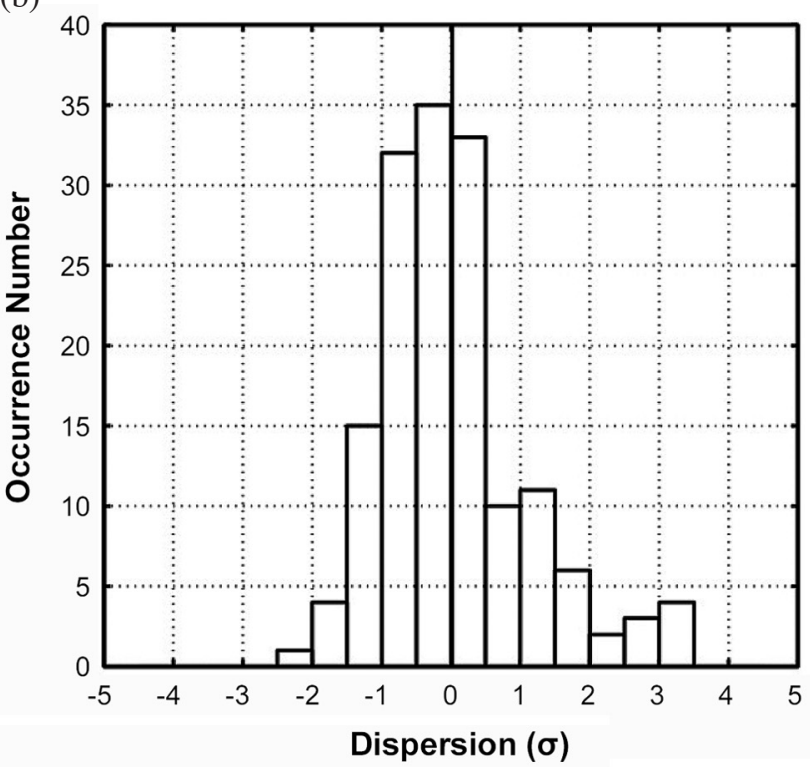

Fig. 6. Occurrence distributions of the (a) trend values and (b) dispersion (with a bin of $0.5 \sigma$ ) during the period from October 1, 2010 to the end of March, 2011.

period from the beginning of October, 2010 to the end of March, 2011. As you can see from this figure, the values of trends and dispersions are found to approximately follow a Gaussian distribution. This means that the usual conversion between the number of $\sigma$ and probability is acceptable. Hence, the value of trend of our anomaly exceeding $-3 \sigma$ or even approaching $-4 \sigma$ level is extremely exceptional.

\section{(2) How Are the Temporal Evolution of Terminator- Times?}

There is another analysis method for VLF/LF propagation data, the terminator time method by Hayakawa et al. (1996) as mentioned before. This method is known to be of extreme importance mainly for short-distance (1 - $2 \mathrm{Mm}$ or so) subionospheric VLF/LF propagation paths.that this method has been used extensively for the studies of VLF/LF anomalies for propagation paths within Japan. Though the propagation distance for our case of NLK-CHF propagation path is moderate on the order of $7.7 \mathrm{Mm}$, we have checked the temporal evolution of the terminator time (morning) because it was difficult to read the evening terminator time. As the result, we have unfortunately found no significant change in the morning terminator time before the EQ. This terminator time method was not so useful to find out any seismo-ionospheric effect for moderate distance propagation paths such as NLK-CHF which is in good agreement with the previous conclusion by Maekawa and Hayakawa (2006).
(3) Any Solar-Terrestrial Effects (Especially the Effect of Geomagnetic Storms) on Our VLF Propagation Anomaly?

The most important point when claiming our VLF/ LF propagation anomaly is likely to be associated with the huge EQ is the investigation of solar-terrestrial effects during the relevant time period. The solar activity as estimated by a F10.7 radio flux has grown two fold (from nearly 80 to nearly 160) over 10 days reaching its maximum on March 8 (though not shown as a graph) which might lead to a tremendous increase of electron density in the daytime ionosphere. Of course, the nighttime electron density we are looking at is also influenced by the daytime condition, so that it might result in the corresponding effect even at night. Our data analysis is based only on nighttime data such that we think that the effect of these solar activities would have some effect on the nighttime data. We have checked the original raw VLF/LF data for a period of February and March, 2011. However, we have not found any significant change even in the daytime VLF/LF amplitude which means the solar-flux increase before March 8 had no effect even on the subionospheric VLF/LF data.

Next, the most profound effect might be geomagnetic storms which we will discuss here. We show our previous extensive study on the effect of geomagnetic storms on VLF/LF propagation (amplitude and phase) (Rozhnoi et al. 2004, 2012a). The geomagnetic activity (Dst) is divided into certain intervals and the number of days with Dst in every interval was calculated (this is $\mathrm{N}$ ). Then in every interval 
among the chosen days we selected days with the average $\mathrm{dA}$ exceeds the $2 \sigma$ level $(\mathrm{Ni})$. The ratio of $\mathrm{Ni} / \mathrm{N}$ is considered to be the sensitivity of VLF/LF signal amplitude to the geomagnetic activity, Dst. They show that the correlation of VLF amplitude with Dst seems to exist. However, the correlation is not so high, so that there exists even a situation that a strong magnetic storm $(\mid$ Dst $\mid=200 \mathrm{nT})$ is accompanied by a small effect, while a rather moderate $(\mid$ Dst $\mid=40 \mathrm{nT})$ storm induces a large anomaly. So that, the best way is to check the raw data carefully.

Figure 7 illustrates the temporal evolution of geomagnetic activity (Dst) in February and March 2011. You can notice two moderate geomagnetic storms: one commencing on March 1 (and ending at $21 \mathrm{~h} \mathrm{UT}$ on March 2) and another commencing on March 10, 2011 (ending UT $=3 \mathrm{~h}$ on March 12). We have also plotted schematically the temporal evolution of our VLF/LF propagation anomaly in the same figure (Fig. 7c). As you can see from a simple comparison of both, our VLF anomaly is located fortunately during a period of low geomagnetic activity, so that the effect of geomagnetic activity on VLF is likely to be extremely small, even though it may be impossible to filter out non-seismic effect completely. However, we have checked the raw original VLF/ LF waveform data in order to find any geomagnetic effect. As suggested by Rozhnoi et al. (2012a), we have found a bay-type anomaly in VLF amplitude at night on March 1,

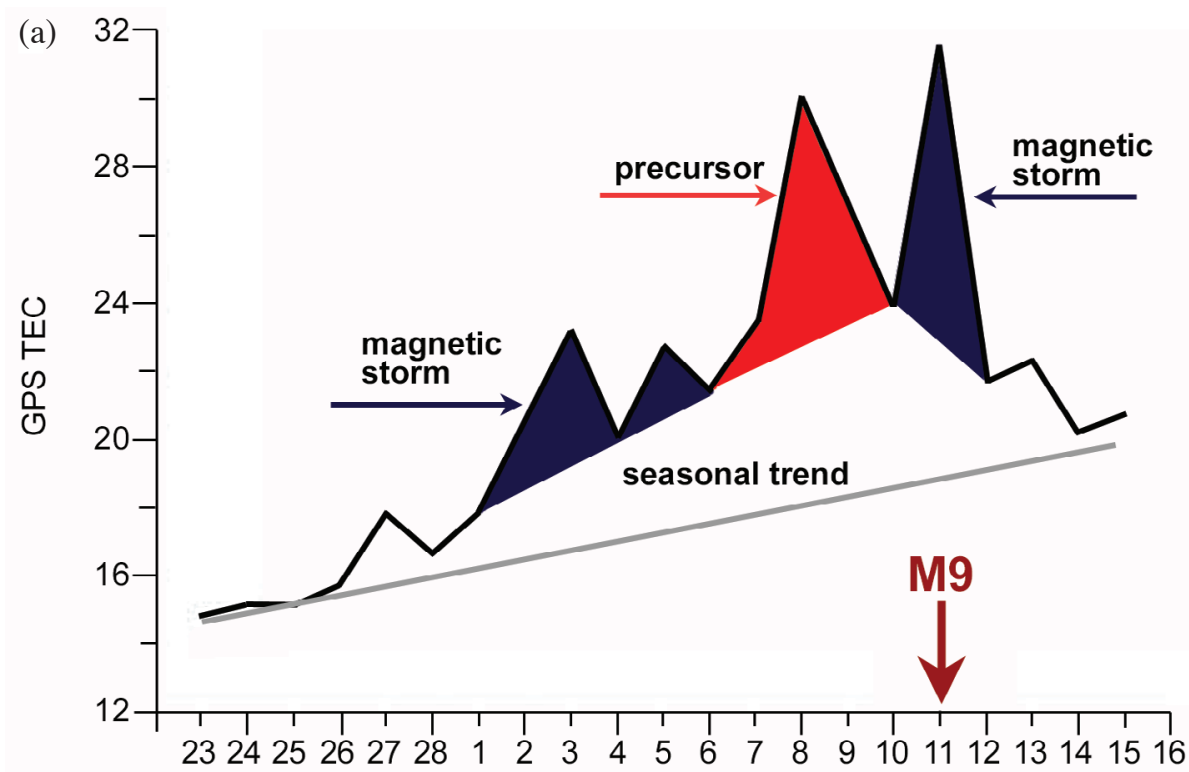

(b)
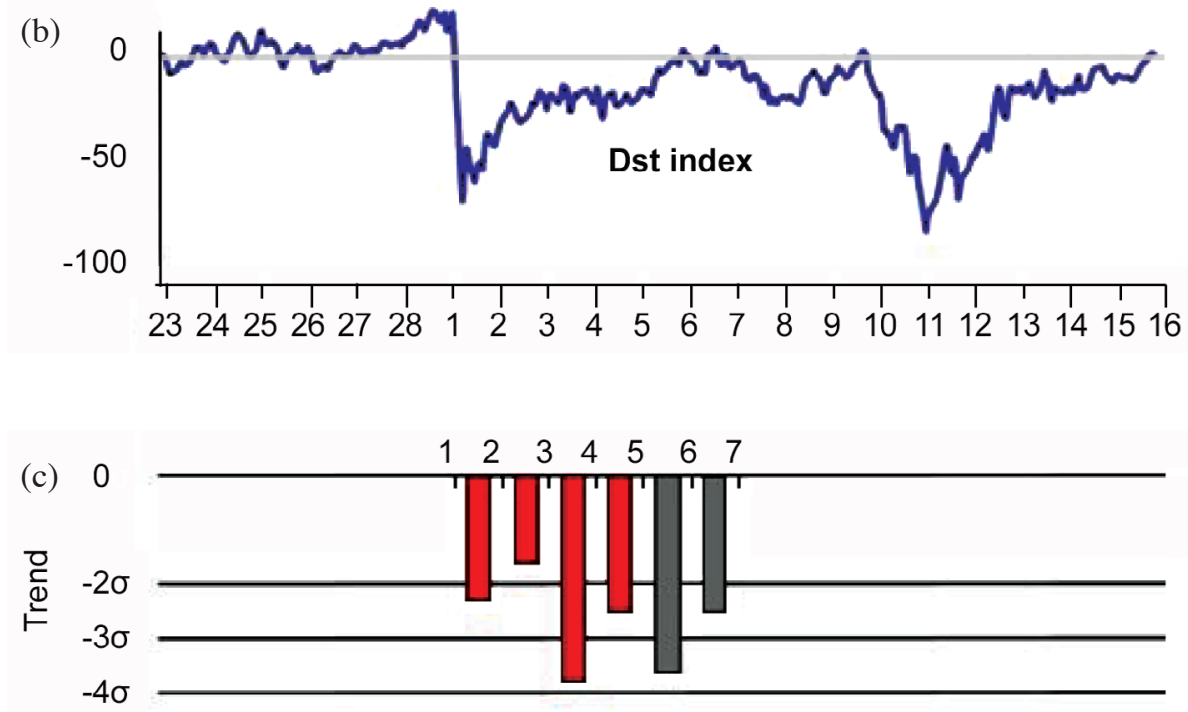

Fig. 7. (a) is the result of GPS/TEC variation (after Ouzounov et al. 2012), (b) is the temporal evolution of geomagnetic activity (Dst) before the EQ, and (c) is our VLF/LF result, indicating the temporal evolution of a combination of NLK-CHF (in grey) and JJI-PTK (in red) anomalies. 
which is probably the consequence of the storm on the same day. No such an anomaly has been observed until the date of EQ. On the other hand, our VLF/LF anomalies on March 5 and 6 are characterized by a prolonged decrease in amplitude during and around the whole night, which are completely different in properties from the geomagnetic- associated bay-like disturbances.

\section{(4) The Effect of Any other EQs and Foreshock Activi- ties on the VLF Anomaly?}

The effect of any other EQs over the propagation path is investigated. Initially we checked the presence of other EQs over the whole region of the relatively long propagation path of NLK-CHF (and KSG and KCH), but we did not find any significant EQs except the 3.11 Japan EQ. The same survey has been done for the propagation path of JJIPTK, but no other EQs were found to be associated with our VLF anomaly.

The collation of Russian with Japanese data has enabled us to locate the region of our VLF anomaly, which would be a strong support for our VLF anomaly to be highly likely to be related with the $3.11 \mathrm{EQ}$.

How about the effect of foreshock activity in the relevant EQ region? Seismic activity, including the M 5.5 event, started one month before the main shock and continued for two weeks in an adjacent area $50 \mathrm{~km}$ northeast of the main shock epicenter (Hirose et al. 2011). Furthermore, the largest foreshock of M 7.3 (March 9) occurred in the same area two days before the M9 main shock (Hirose et al. 2011). These EQs were interplate EQs like the main shock because the focal mechanisms determined also indicate a reverse fault type, the same as the main shock. As can be seen from Fig. 4a, there is a period just around the end of February to early March, for which the trend shows a tendency of prolonged depletion. This phenomenon might be associated with foreshock activities.

\section{(5) Any Correlation of the VLF Anomaly with Other Related Phenomena?}

In order to enhance the reliability of our VLF/LF anomaly, we try to compare our VLF anomaly with any other atmospheric and ionospheric phenomena. Ouzounov et al. (2012) studied the upper ionospheric electron density using GPS/TEC (Total electron contents) methods. They found a significant anomaly, an increase in electron content on March 8 and the same tendency for a few days before this date which they attribute to a seismogenic origin. This is also plotted in Fig. 7a as well. The approximate coincidence in time of the GPS/TEC anomaly with our VLF anomaly might indicate that the ionosphere seems to be disturbed as a pre-EQ effect not only in the lower ionosphere, but also in the upper ionosphere.

\section{(6) Any Other Examples of VLF/LF Propagation Anomaly for Oceanic EQs}

Though we have a huge number of VLF/LF anomaly events for inland (or fault-related) EQs (Maekawa et al. 2006; Kasahara et al. 2008; Hayakawa et al. 2010a, b), the number of events for oceanic (or plate-type ) EQs is not so abundant, but we can list few events. One of the most typical example of oceanic EQs is the 2004 Sumatra EQ (Horie et al. 2007a, b) and, the nighttime fluctuation method as used in this paper was found to be effective in finding out seismo-ionospheric perturbations even though the EQ epicenter is far $(\sim 2000 \mathrm{~km})$ from the propagation path from the Australian NWC transmitter to Japanese stations

Further examples for seismo-ionospheric perturbations for oceanic EQs in the Asian region have been obtained from the same propagation paths from the NWC transmitter to Japanese stations (propagation distance $=6-8 \mathrm{Mm}$ nearly close to the distance of NLK-CHF path) (Kasahara et al. 2010). They have analyzed five huge oceanic EQs (with a magnitude greater than 6.0). Among the five events, they have found that the trend exhibits a significant decrease (exceeding $-3 \sigma$ ) at $\mathrm{KCH}$ (Kochi), a decrease exceeding $-2 \sigma$ at CHF for a major EQ with $\mathrm{M}=7.3($ depth $=30 \mathrm{~km}$ ) nearly along the great-circle. This anomaly is known to take place again one to two weeks before the EQ. The duration is considerably long, on the order of a week.

Recently we have added one more example for a huge sea EQ (the Simushur EQ in the Kurile Islands on November 15, 2006, $\mathrm{M}=8.3$ ) (Rozhnoi et al. 2012b). This EQ is similar to the present 3.11 EQ, in the sense that the EQ is an oceanic plate-type EQ and also the EQ magnitude is large, 8.3. We have used the same nighttime fluctuation method and, we have found significant anomalies on the two paths; JJI-PTK (as shown in Fig. 2) and NWC (Australia)-PTK. The VLF/LF anomalies start about two weeks before the main shock as a decrease in trend and continue during the aftershock activity.

Since it is likely that the anomaly in the VLF propagation on March 3 - 6 [Point (2)] may be associated with the $3.11 \mathrm{EQ}$, we will discuss the properties of those VLF anomalies, and their temporal and spatial characteristics. As summarized as Point (2), the conspicuous anomaly in VLF propagation (especially two perturbed paths NLK-CHF and JJI-PTK) is characterized by a significant decrease in trend and a simultaneous enhancement in dispersion for this oceanic EQ. Though this EQ is an exceptionally huge oceanic EQ with the plate-type just around Japan, these properties are found to be exactly the same as those for a huge number of land EQs we worked extensively for years (e.g., Hayakawa 2009c; Hayakawa et al. 2010a). The anomaly on the NLK-CHF path is very conspicuous in the sense that the trend as the nighttime average amplitude shows a remarkable depletion exceeding $-3 \sigma$ (or even more) on March 5 and 6 , and also the corresponding anomaly is seen on the 
path of JJI-PTK on March 3 and 4, with the corresponding decrease in trend below $-2 \sigma$. A slight shift in the temporal response for different paths is not so meaningful, probably because of the different spatial and temporal changes within the ionospheric disturbance. The lead time of our VLF/LF propagation anomaly is estimated to be $8-5$ days. The mean is about 7 days. This value also seems to be very consistent with that for the inland EQs (Hayakawa et al. 2010a).

Finally, we will repeat that the characteristics of propagation anomaly are nearly the same for both oceanic and inland EQs, including the depression in trend, together with enhancement in dispersion, and the lead time.

Then we will discuss the spatial characteristies of the seismo-ionospheric perturbation. As is summarized by Point (1), the path of JJI-YSH is very far away from the EQ epicenter, so that it is easy for us to consider theoretically that there might be no expected anomaly. The wave sensitive areas of two unperturbed paths of JJY to MSR and JJY to YSH are not found to cover the EQ epicenter, which is a possible reason why we have not observed any significant propagation anomalies for these two paths (JJY-MSR and JJY-YSH). In good correspondence with this expectation,
Point (2) indicates that the EQ epicenter is well located inside the wave sensitive areas of the two paths of NLK-CHF (and KSG and $\mathrm{KCH}$ ) and JJI-PTK such that we have detected clear significant propagation anomalies on these two paths. We have drawn the possible region of ionospheric perturbations in Fig. 8 as estimated by the overlapping of disturbed propagation paths, in which it is quite uncertain how farther the north-east boundary of the perturbed region is extended. Anyway the spatial scale of the ionospheric perturbation for the 3.11 Japan EQ is extremely small of the order of $\geq 1 \mathrm{Mm}$ in diameter or so. This value seems to be relatively small even as compared with the spatial scale for the 1995 Kobe EQ (with $M=7.2$ ). If we use the empirical or theoretical formula of the perturbation scale in relation to EQ magnitude (Dobrovolsky et al. 1979; Ruzhin and Depueva 1996), the present spatial scale would correspond to $\mathrm{M} \sim 6.4$, surprisingly small as compared with the real magnitude. Now we compare this spatial scale with that for the 2004 Sumatra EQ with nearly the same magnitude as this $3.11 \mathrm{EQ}$. Based on the ground-based observations in Japan (Horie et al. 2007a, b) for the propagation paths associated with the Australian NWC transmitter and also the

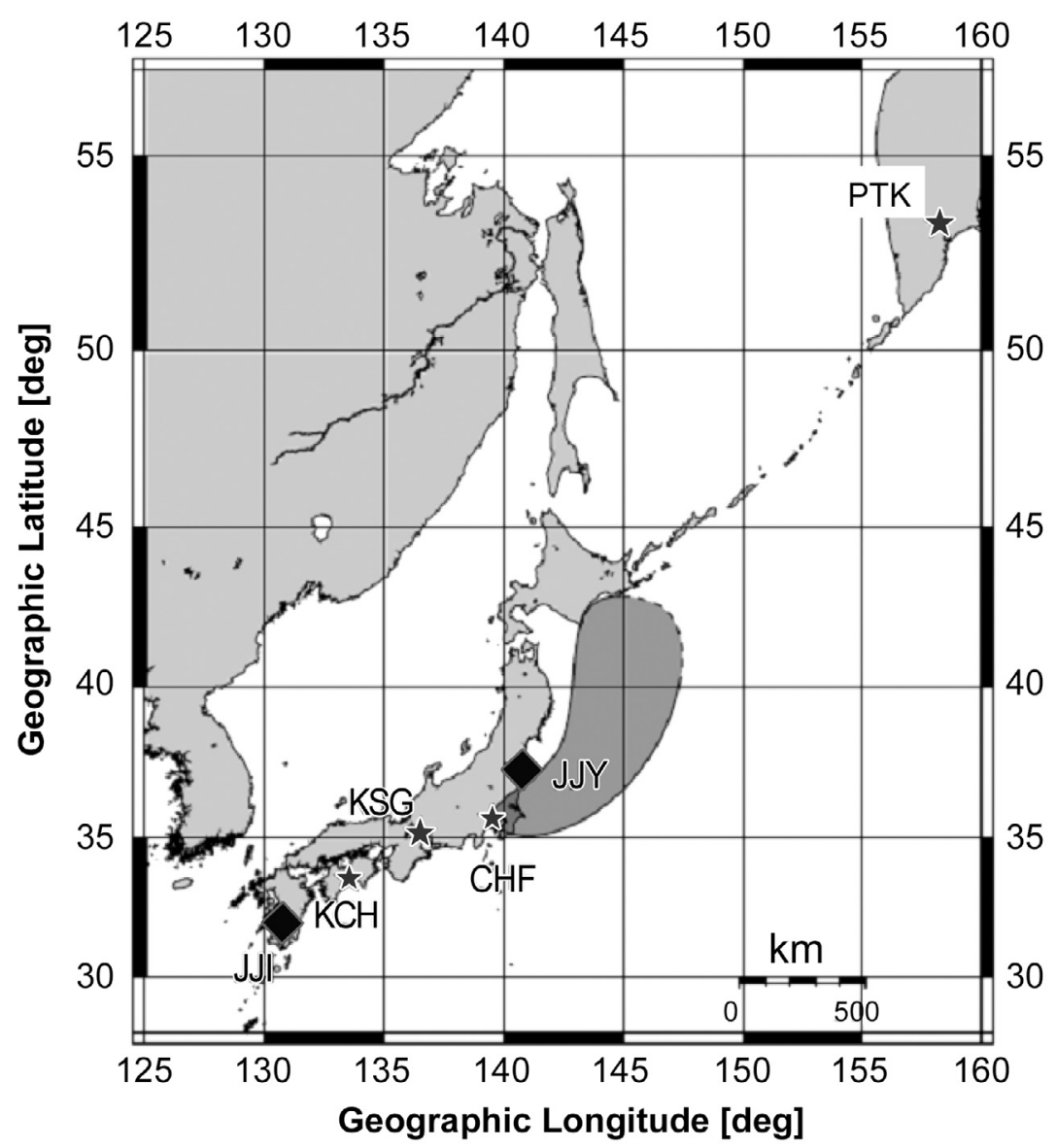

Fig. 8. Illustration of the possible suggested region of the precursory seismo-ionospheric perturbation for the $3.11 \mathrm{EQ}$ as inferred from a combination of propagation characteristics of all propagation paths we have studied. However, the north-east extension is quite uncertain. 
satellite observation of whistler-mode signals from the same transmitter (Molchanov et al. 2006). We have found that the radius of the ionospheric perturbation is on the order of 2.5 Mm for the Sumatra EQ. Hence the radius for this Japan EQ is extremely small as compared with that for the 2004 Sumatra EQ. The Sumatra EQ is also an oceanic EQ of the plate type, the same type as the 3.11 Tohoku EQ, but the most important difference between the two is that the Sumatra EQ happened very close to the land area of Indonesia, whereas the Tohoku EQ happened far away $(\sim 150 \mathrm{~km})$ from the coast line and happened exactly in the sea.

As shown in Fig. 8, the spatial shape of the seismoperturbation in the lower ionosphere is found to be structured very parallel to the Japan land area, or it seems to be structured closely along the rupture region of this EQ. In fact, the aftershock activity covered a wide range of $500 \mathrm{~km}$ (in NS direction) and $200 \mathrm{~km}$ (in EW direction) (Hirose et al. 2011), and the perturbed ionospheric region in Fig. 8 is likely to overlap with those rupture (or aftershocks) regions.

Finally, we comment on the generation mechanism on why and how the ionospheric perturbation is formed due to the pre-EQ activity (Hayakawa et al. 2010a). There a few plausible hypotheses have been proposed: (1) chemical (+ electric field) channel (e.g., Pulinets and Boyarchuk 2004; Sorokin et al. 2006), (2) atmospheric oscillation channel (e.g., Molchanov et al. 2001; Miyaki et al. 2002; Hayakawa et al. 2004, 2011; Molchanov and Hayakawa 2008) and (3) electrostatic channel due to positive hole carriers (Freund 2009).

It is not perfectly established which mechanism is dominant, though we are in a position in favor to support the second hypothesis (Hayakawa et al. 2011). According to a recent DEMETER paper by Parrot (2012) on the statistical analysis of the ion density of the ionosphere, he has found that there are more perturbations for EQs with their epicenter below the sea and also that the intensity of perturbations is more enhanced for sea EQs than for inland EQs. Our propagation path of NLK-CHF is about 7.7 Mm unlike the short path (1 - $2 \mathrm{Mm})$ within Japan, so that the perturbed region is only a small fraction of the whole propagation path. Even in this situation, we have detected an exceptionally large depletion in amplitude (trend) exceeding $-3 \sigma \sim-4 \sigma$. This may suggest that the degree of perturbation (e.g., a large amount of lowering of the lowest ionosphere as compared with the conventional value) might be tremendous for sea EQs, which seems to be consistent with Parrot's (2012) result. Of course, the detailed computational work is highly required to prove this. Then, our spatial scale cannot be compared with the satellite result because no information on the spatial scale is obtained by Parrot (2012). No matter which mechanism (either chemical, atmospheric oscillation or electrostatic channel) is operating for the generation of seismo-ionospheric perturbation, we think that the ground is more important than the sea in the sense of generating the electric field in the first and third channels or exciting the atmospheric oscillations in the second channel. However, Fig. 8 suggests that the ionospheric perturbation is seen mainly over the sea which would oblige us to perform further extensive study (either experimentally or theoretically) to explain the ionospheric characteristics for this oceanic EQ in the sense of comparing with those of land EQs.

Acknowledgements The observation by Russian colleagues is supported by FP7 grant SEMEP, to which we are thankful. The Japanese work was, in part, supported by NICT (National Institute of Information and Communications Technology), Japan and Mayekawa Houonkai Foundation to which we are grateful.

\section{REFERENCES}

Cervone, G., S. Maekawa, R. P. Singh, M. Hayakawa, M. Kafatos, and A. Shvets, 2006: Surface latent heat flux and nighttime LF anomalies prior to the $\mathrm{M}_{\mathrm{w}}=8.3$ Tokachi-oki earthquake. Nat. Hazards Earth Syst. Sci., 6, 109-114, doi: 10.5194/nhess-6-109-2006. [Link]

Chakrabarti, S. K., 2010: Propagation Effects of Very Low Frequency Radio Waves. AIP Conference Proceedings, Publisher: American Institute of Physics, 372 pp.

Dobrovolsky, I. P., S. I. Zubkov, and V. I. Miachkin, 1979: Estimation of the size of earthquake preparation zones. Pure Appl. Geophys., 117, 1025-1044, doi: 10.1007/ BF00876083. [Link]

Fraser-Smith, A. C., 2009: The ultra-low-frequency magnetic fields associated with and preceding earthquakes. In: Hayakawa, M. (Ed.), Electromagnetic Phenomena Associated with Earthquakes, Transworld Research Network, Trivandrum India, 1-20.

Freund, F., 2009: Stress-activated positive hole change carriers in rocks and the generation of pre-earthquake signals. In: Hayakawa, M. (Ed.), Electromagnetic Phenomena Associated with Earthquakes, Transworld Research Network, Trivandrum India, 41-96.

Gokhberg, M. B., I. L. Gufeld, A. A. Rozhnoy, V. F. Marenko, V. S. Yampolsky, and E. A. Ponomarev, 1989: Study of seismic influence on the ionosphere by super long-wave probing of the Earth-ionosphere waveguide. Phys. Earth Planet. Inter., 57, 64-67, doi: 10.1016/00 31-9201(89)90214-8. [Link]

Gufeld, I. L., A. A. Rozhnoy, S. N. Tyumentsev, S. V. Sherstyuk, and V. S. Yampolsky, 1992: Radio wave field disturbances prior to Rudbar and Rachinsk earthquakes. Izvestiya, Phys. Solid Earth, 28, 267-270.

Hayakawa, M., 1999: Atmospheric and Ionospheric Electromagnetic Phenomena Associated with Earthquakes, Terra Scientific Pub. Co., Tokyo, 996 pp.

Hayakawa, M., 2009a: Electromagnetic Phenomena Associated with Earthquakes, Transworld Research Network, 
Trivandrum India, $279 \mathrm{pp}$.

Hayakawa, M., 2009b: Seismogenic pertubation in the atmosphere. In: Hayakawa M. (Ed.), Electromagnetic Phenomena Associated with Earthquakes, Transworld Research Network, Trivandrum India, 119-136.

Hayakawa, M., 2009c: Lower ionospheric pertubations associated with earthquakes, as detected by subionospheric VLF/LF radio waves. In: Hayakawa M. (Ed.), Electromagnetic Phenomena Associated with Earthquakes, Transworld Research Network, Trivandrum India, 137-185.

Hayakawa, M., 2012: The Frontier of Earthquake Prediction Studies, Nihon- senmontosho-Shuppan, Tokyo, $800 \mathrm{pp}$.

Hayakawa, M. and O. A. Molchanov, 2002: Seismo Electromagnetics: Lithosphere - Atmosphere - Ionosphere Coupling, TERRAPUB, Tokyo, $477 \mathrm{pp}$.

Hayakawa, M. and Y. Hobara, 2010: Current status of seismo-electromagnetics for short-term earthquake prediction. Geomatics, Nat. Hazards Risk, 1, 115-155, doi: 10.1080/19475705.2010.486933. [Link]

Hayakawa, M., O. A. Molchanov, T. Ondoh, and E. Kawai, 1996: The precursory signature effect of the Kobe earthquake on VLF subionospheric signals. J. Comm. Res. Lab., Tokyo, 43, 169-180.

Hayakawa, M., O. A. Molchanov, NASDA/UEC team, 2004: Summary report of NASDA's earthquake remote sensing frontier project. Phys. Chem. Earth, 29, 617-625, doi: 10.1016/j.pce.2003.08.062. [Link]

Hayakawa, M., K. Ohta, A. P. Nickolaenko, and Y. Ando, 2005: Anomalous effect in Schumann resonance phenomena observed in Japan, possibly associated with the Chi-chi earthquake in Taiwan. Ann. Geophys., 23, 1335-1346, doi: 10.5194/angeo-23-1335-2005. [Link]

Hayakawa, M., K. Ohta, S. Maekawa, T. Yamauchi, Y. Ida, T. Gotoh, N. Yonaiguchi, H. Sasaki, and T. Nakamura, 2006: Electromagnetic precursors to the $2004 \mathrm{Mid}$ Niigata Prefecture earthquake. Phys. Chem. Earth, 31, 356-364, doi: 10.1016/j.pce.2006.02.023. [Link]

Hayakawa, M., K. Hattori, and K. Ohta, 2007: Monitoring of ULF (ultra-low-frequency) geomagnetic variations associated with earthquakes. Sensors, 7, 1108-1122, doi: 10.3390/s7071108. [Link]

Hayakawa, M., Y. Kasahara, T. Nakamura, F. Muto, T. Horie, S. Maekawa, Y. Hobara, A. A. Rozhnoi, M. Solovieva, and O. A. Molchanov, 2010a: A statistical study on the correlation between lower ionospheric perturbations as seen by subionospheric VLF/LF propagation and earthquakes. J. Geophys. Res., 115, A09305, doi: 10.1029/2009JA015143. [Link]

Hayakawa, M., Y. Kasahara, T. Nakamura, Y. Hobara, A. Rozhnoi, M. Solovieva, O. A. Molchanov, 2010b: On the correlation between ionospheric perturbations as detected by subionospheric VLF/LF signals and earthquakes as characterized by seismic intensity. J. Atmos.
Sol.-Terr. Phys., 72, 982-987, doi: 10.1016/j.jastp.20 10.05.009. [Link]

Hayakawa, M., T. Horie, F. Muto, Y., Kasahara, K. Ohta, J. Y. Liu, and Y. Hobara, 2010c: Subionospheric VLF/ LF probing of ionospheric perturbations associated with earthquakes: A possibility of earthquake prediction. SICE JCMSI, 3, 10-14.

Hayakawa, M., Y. Kasahara, T. Nakamura, Y. Hobara, A. Rozhnoi, M. Solovieva, O. A. Molchanov, and V. Korepanov, 2011: Atmospheric gravity waves as a possible candidate for seismo-ionospheric perturbations. J. Atmos. Electr., 31, 129-140.

Hayakawa, M., Y. Hobara, Y. Yasuda, H. Yamaguchi, K. Ohta, J. Izutsu, and T. Nakamura, 2012: Possible precursor to the March 11, 2011, Japan earthquake: ionospheric perturbations as seen by subionospheric very low frequency/low frequency propagation. Ann. Geophys., 55, 95-99, doi: 10.4401/ag-5357. [Link]

Hirose, F., K. Miyaoka, N. Hayashimoto, T. Yamazaki, and M. Nakamura, 2011: Outline of the 2011 off the Pacific coast of Tohoku earthquake (Mw 9.0) - Seismicity: Foreshocks, mainshock, aftershocks, and induced activity. Earth Planets Space, 63, 513-518, doi: 10.5047/ eps.2011.05.019. [Link]

Horie, T., S. Maekawa, T. Yamauchi, and M. Hayakawa, 2007a: A possible effect of ionospheric perturbations associated with the Sumatra earthquake, as revealed from subionospheric very-low-frequency (VLF) propagation (NWC-Japan). Int. J. Remote Sens., 28, 31333139, doi: 10.1080/01431160601094476. [Link]

Horie, T., T. Yamauchi, M. Yoshida, and M. Hayakawa, 2007b: The wave-like structures of ionospheric perturbation associated with Sumatra earthquake of 26 December 2004, as revealed from VLF observation in Japan of NWC signals. J. Atmos. Sol.-Terr. Phys., 69, 1021-1028, doi: 10.1016/j.jastp.2007.03.012. [Link]

Kasahara, Y., F. Muto, T. Horie, M. Yoshida, M. Hayakawa, K. Ohta, A. Rozhnoi, M. Solovieva, and O. A. Molchanov, 2008: On the statistical correlation between the ionospheric perturbations as detected by subionospheric VLF/LF propagation anomalies and earthquakes. Nat. Hazards Earth Syst. Sci., 8, 653-656, doi: 10.51 94/nhess-8-653-2008. [Link]

Kasahara, Y., F. Muto, Y. Hobara, and M. Hayakawa, 2010: The ionospheric perturbations associated with Asian earthquakes as seen from the subionospheric propagation from NWC to Japanese stations. Nat. Hazards Earth Syst. Sci., 10, 581-588, doi: 10.5194/nhess-10581-2010. [Link]

Kopytenko, Y. A., V. S. Ismaguilov, and L. V.Nikitina, 2009: Study of local anomalies of ULF magnetic disturbances before strong earthquakes and magnetic fields induced by tsunami. In: Hayakawa, M. (Ed.), Electromagnetic Phenomena Associated with Earthquakes, Transworld 
Research Network, Trivandrum India, 21-40.

Liu, J. Y., 2009: Earthquake precursors observed in the ionospheric F-region. In: Hayakawa, M. (Ed.), Electromagnetic Phenomena Associated with Earthquakes, Transworld Research Network, Trivandrum India, 187204.

Liu, J. Y., Y. I. Chen, Y. J. Chuo, and C. S. Chen, 2006: A statistical investigation of preearthquake ionospheric anomaly. J. Geophys. Res., 111, A05304, doi: 10.1029/2005JA011333. [Link]

Maekawa, S. and M. Hayakawa, 2006: A statistical study on the dependence of characteristics of VLF/LF terminator times on the propagation direction. IEEJ Trans. Fund. Mater., 126, 220-226, doi: 10.1541/ieejfms.126.220. [Link]

Maekawa, S., T. Horie, T. Yamauchi, T. Sawaya, M. Ishikawa, M. Hayakawa, and H. Sasaki, 2006: A statistical study on the effect of earthquakes on the ionosphere, based on the subionospheric LF propagation data in Japan. Ann. Geophys., 24, 2219-2225, doi: 10.5194/ angeo-24-2219-2006. [Link]

Miyaki, K., M. Hayakawa, and O. A. Molchanov, 2002: The role of gravity waves in the lithosphere - Ionosphere coupling, as revealed from the subionospheric LF propagation data. In: Hayakawa, M. and O. A. Molchanov (Eds.), Seismo Electromagnetics: LithosphereAtmosphere-Ionosphere Coupling, TERRAPUB, Tokyo, 229-232.

Molchanov, O. A. and M. Hayakawa, 2008: Seismo Electromagnetics and Related Phenomena: History and Latest Results, TERRAPUB, Tokyo, 189 pp.

Molchanov, O. A., M. Hayakawa, and K. Miyaki, 2001: VLF/LF sounding of the lower ionosphere to study the role of atmospheric oscillations in the lithosphereionosphere coupling. Adv. Polar Upper Atmos. Res., 15, 146-158.

Molchanov, O., A. Rozhnoi, M. Solovieva, O. Akentieva, J. J. Berthelier, M. Parrot, F. Lefeuvre, P. F. Biagi, L. Castellana, and M. Hayakawa, 2006: Global diagnostics of the ionospheric perturbations related to the seismic activity using the VLF radio signals collected on the DEMETER satellite. Nat. Hazards Earth Syst. Sci., 6, 745-753, doi: 10.5194/nhess-6-745-2006. [Link]

Muto, F., Y. Kasahara, Y. Hobara, M. Hayakawa, A. Rozhnoi, M. Solovieva, and O. A. Molchanov, 2009: Further study on the role of atmospheric gravity waves on the seismo-ionospheric perturbations as detected by subionospheric VLF/LF propagation. Nat. Hazards Earth Syst. Sci., 9, 1111-1118, doi: 10.5194/nhess-91111-2009. [Link]

Ouzounov, D., S. Pulinets, K. Hattori, M. Kafatos, and P. Taylor, 2012: Atmospheric signals associated with major earthquakes: A multi-sensor approach. In: Hayakawa, M. (Ed.), The Frontier of Earthquake Prediction Stud- ies, Nihon-senmontosho-Shuppan, Tokyo, 510-531.

Parrot, M., 2009: Anomalous seismic phenomena: View from space. In: Hayakawa, M. (Ed.), Electromagnetic Phenomena Associated with Earthquakes, Transworld Research Network, Trivandrum India, 205-234.

Parrot, M., 2012: Statistical analysis of the ion density measured by the satellite DEMETER in relation with the seismic activity. Earthq. Sci., 24, 513-521, doi: 10.1007/s11589-011-0813-3. [Link]

Pulinets, S. A. and K. Boyarchuk, 2004: Ionospheric Precursors of Earthquakes, Springer, Berlin, 215 pp.

Rozhnoi, A., M. S. Solovieva, O. A. Molchanov, and M. Hayakawa, 2004: Middle latitude LF (40 kHz) phase variations associated with earthquakes for quiet and disturbed geomagnetic conditions. Phys. Chem. Earth, 29, 589-598, doi: 10.1016/j.pce.2003.08.061. [Link]

Rozhnoi, A., M. Solovieva, O. Molchanov, P.-F. Biagi, and M. Hayakawa, 2007: Observation evidences of atmospheric gravity waves induced by seismic activity from analysis of subionospheric LF signal spectra. Nat. Hazards Earth Syst. Sci., 7, 625-628, doi: 10.5194/nhess7-625-2007. [Link]

Rozhnoi, A., M. Solovieva, and M. Hayakawa, 2012a: Search for electromagnetic earthquake precursors by means of sounding of upper atmosphere-lower ionosphere boundary by VLF/LF signals. In: Hayakawa, M. (Ed.), The Frontier of Earthquake Prediction Studies, Nihon-senmontosho-Shuppan, Tokyo, 652-677.

Rozhnoi, A., M. Solovieva, M. Parrot, M. Hayakawa, P. F. Biagi, and K. Schwingenschuh, 2012b: Ionospheric turbulence from ground-based and satellite VLF/LF transmitter signal observations for the Simushir earthquake (November 15, 2006). Ann. Geophys., 55, 187192, doi: 10.4401/ag-5190. [Link]

Ruzhin, Y. Y. and A. K. Depueva, 1996: Seismo precursors in space as plasma and wave anomalies. J. Atmos. Electr., 16, 271-288.

Shvets, A. V., M. Hayakawa, and S. Maekawa, 2004: Results of subionospheric radio LF monitoring prior to the Tokachi (M=8, Hokkaido, 25 September 2003) earthquake. Nat. Hazards Earth Syst. Sci., 4, 647-653, doi: 10.5194/nhess-4-647-2004. [Link]

Sorokin, V. M., A. K. Yaschenko, V. M. Chmyrev, and M. Hayakawa, 2006: DC electric field amplification in the mid-latitude ionosphere over seismically active faults. Phys. Chem. Earth, 31, 447-453, doi: 10.1016/ j.pce.2006.02.021. [Link]

Uyeda, S., T. Nagao, K. Hattori, Y. Noda, M. Hayakawa, K. Miyaki, O. Molchanov, V. Gladychev, L. Baransky, A. Schekotov, G. Belyaev, E. Fedorov, O. Pokhotelov, S. Andreevsky, A. Rozhnoi, Y. Khabazin, A. Gorbatikov, E. Gordeev, V. Chebrov, A. Lutikov, S. Yunga, G. Kosarev, and V. Surkov, 2002: Russian-Japanese complex geophysical observatory in Kamchatka for 
monitoring of phenomena connected with seismic activity. In: Hayakawa, M. and O. A. Molchanov (Eds.), Seismo Electromagnetics: Lithosphere-AtmosphereIonosphere Coupling, TERRAPUB, Tokyo, 413-419.

Uyeda, S., T. Nagao, and M. Kamogawa, 2009: Shortterm earthquake prediction: Current status of seismoelectromagnetics. Tectonophysics, 470, 205-213, doi: 10.1016/j.tecto.2008.07.019. [Link]
Varotsos, P., 2005: The Physics of Seismic Electric Signals, TERRAPUB, Tokyo, 329 pp.

Yamauchi, T., S. Maekawa, T. Horie, M. Hayakawa, and O. Soloviev, 2007: Subionospheric VLF/LF monitoring of ionospheric perturbations for the $2004 \mathrm{Mid}-\mathrm{Ni}$ igata earthquake and their structure and dynamics. $J$. Atmos. Sol.-Terr. Phys., 69, 793-802, doi: 10.1016/j. jastp.2007.02.002. [Link] 